\title{
INFLUENCE OF SELECTED TECHNOLOGICAL FACTORS ON THE Hole Quality DURING REAMing
}

\author{
Jaroslava Fulemova, Jan Kutlwaser, Miroslav Gombar \& Jan Rehor
}
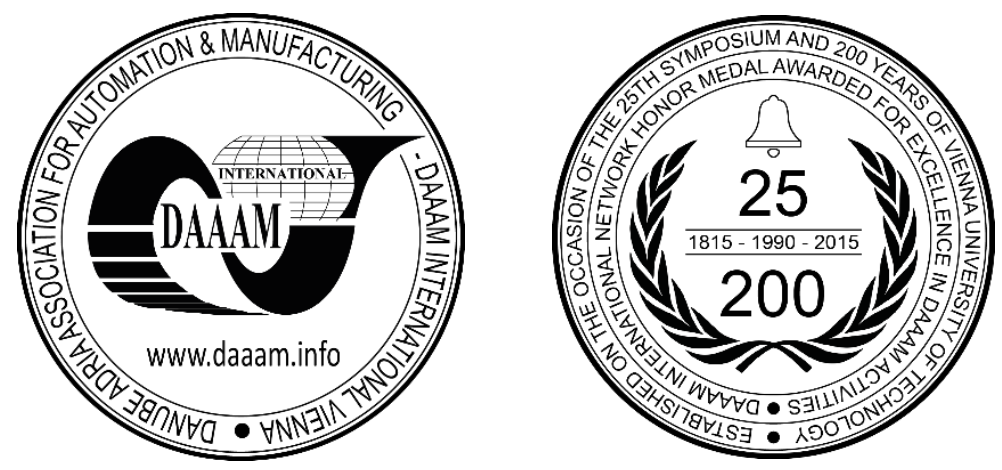

This Publication has to be referred as: Fulemova, J[aroslava]; Kutlwaser, J[an]; Gombar, M[iroslav] \& Rehor, J[an] (2017). Influence of Selected Technological Factors on the Hole Quality During Reaming, Proceedings of the 28th DAAAM International Symposium, pp.0334-0340, B. Katalinic (Ed.), Published by DAAAM International, ISBN 9783-902734-11-2, ISSN 1726-9679, Vienna, Austria

DOI: $10.2507 / 28$ th.daaam.proceedings.046

\begin{abstract}
Quality of reamed hole is influenced by many factors. Some of them have higher impact on accuracy and quality of reamed hole and the others have higher impact on tool life of a reamer. This article deals with influence of cutting speed, feed rate, reverse feed rate and eccentricity of the tool tip on cylindricity, surface roughness Ra and diameter of reamed hole. Design of experiment was carried out with CCD (Central Composite Design) with orthogonal blocking. As a tool was used cermet reamer with 6 brazed cutting edges. Results showed not only valuable data but also weaknesses of experiment preparation. The article also point out weaknesses and how to handle with them.
\end{abstract}

Keywords: Reaming; Design of Experiment; hole quality; machining parameters

\section{Introduction}

Reaming is well known technology for producing precise and very precise holes. The aim of reaming is increasing accuracy to shape and accuracy to size. Reamed holes are produced with very tight tolerance and with fine surface roughness. Generally, reamed hole can be produced in grade of accuracy from IT 5 to IT8 and the quality of machined surface up to Ra 0.4. Although reaming is finishing technology there can be demand for more precise holes (lower than IT 5 and $\mathrm{Ra}$ 0.4), then it is necessary to use the other technological operations like grinding, rolling, honing, etc. [1], [2].

To produce precise hole means a number of technological operations. First of all it is drilling. Accuracy grade of drilled hole is from IT9 to IT12, so it is roughing technology. After that it is boring or chamfering. At the end is reaming. In every step of the production chain is possible to make many mistakes which can influence accuracy and quality of reamed hole.

\subsection{Problem statement}

A part of results, which are presented in this paper, can be found in diploma thesis [3] and they belong to project Ro RTI A7. This project is focused on determination of all factors which can influence quality of reamed hole. The main idea of the project is based on basic research whose results will provide information for practical application. Results of 
literature research provide answer to a few specific problems and give general information about geometry and function of reamers. But nowhere is written which parameter influences the quality of reamed hole. This article tries to determine factors which can influence hole quality during reaming by using DoE (design of experiment) and at the same time draw attention to weaknesses of experiment preparation.

\subsection{Literature research}

Bhattacharyya et al. [4] designed mechanistic model to predict cutting forces for arbitrary reamer geometry. Input parameters for this model are reamer geometry, feed rate, cutting speed, initial hole geometry, process faults including parallel offset runout, spindle tilt, respective locating angles and tool/hole axis misalignment. Mechanistic model will predict torque, feed and radial force. The model valid over range of feed rate, cutting speed and varying reamer geometry. Designed model was validated by experiment. They found that parallel offset runout, spindle tilt, spindle tilt locating angle, and tool/hole axis misalignment have significant effects on the radial forces. These radial forces are shown to be correlated to hole quality. [4]

Hauer et al. [5] investigated the influence of a diagonal pre-drilled hole on hole quality during reaming using multiblade tool. Presumption of their research ware following. The varying input parameters are influencing the width of cut and thus the quality of reamed hole. Interaction between positional tolerance of pre-drilled hole and the positioning accuracy of the machine tool lead to varying depth of cut and thereby higher radial force. Finally reaming tool is deflected and the hole quality worsens. They prepared experiment to find out radial deviation of pre-drilled hole made by two different types of drills. The results showed that smaller radial deviation has solid carbide drill than drill with replacable head. After that this pre-drilled holes were reamed to find out if the reamer follows pre-drilled hole. This theoretical presumption was not validated. [5]

Towfighian et al. [6] observed the influence of low speed reaming on vibrations of reamer with modified geometry. Designed FEM predict vibrations. The lobbed of multi-cornered holes are formed during low speed reaming. On the other hand tool chatter occurs at high speed reaming. They found out that irregular spacing of 6 cutting edged leads to perfect hole quality and the best combination of pitch angles also leads to the most stable condition. [6]

Bezerra et al. [7] investigated the influence of cutting parameters (depth of cut, cutting speed, feed rate, helix angle, number of blades, margin size and rake face) on real diameter, roundness, cylindricity and surface roughness during reaming aluminium-silicon alloy. They used reamer with brazed cutting edges from sintered carbide K10. Conclusion was following. Satisfactory hole quality can be achieved by smaller values depth of cut, lower cutting speed, higher feed rate, straight flute reamer with many blades and small margins. It is a paper which describes the whole factors very deeply. [7]

Müller et al. [8] used DoE for set up parameters of reaming to achieve parameters of machined surface and hole tolerance. They were focused on three factors (spindle speed, feed rate and lubrication) on two levels. As design of experiment was used full factorial experiment. The results show that at small spindle speed, feed rate and lubrication with oil the deviation of diameters is smaller than at high spindle speed. When they used lower spindle speed, feed rate and oil lubrication the surface roughness was lower than with higher parameters of cutting process and lubrication with cooling lubricant at $1 \%$ concentration. [8]

\section{Experiment}

Experiment was done on turn-mill complete machining centre CTX beta 1250 TC 4A. As a workpiece was used a bar stock with diameter $30 \mathrm{~mm}$ and length $550 \mathrm{~mm}$. Final length of workpiece was $59 \mathrm{~mm}$. The machine tool and workpiece are in the Fig. 1. The bar stock was clamped into three-jaw chuck and was made of 42CrMo4 steel. Chemical composition and mechanical properties are in Table 1 . This material is very often used for tool holders.
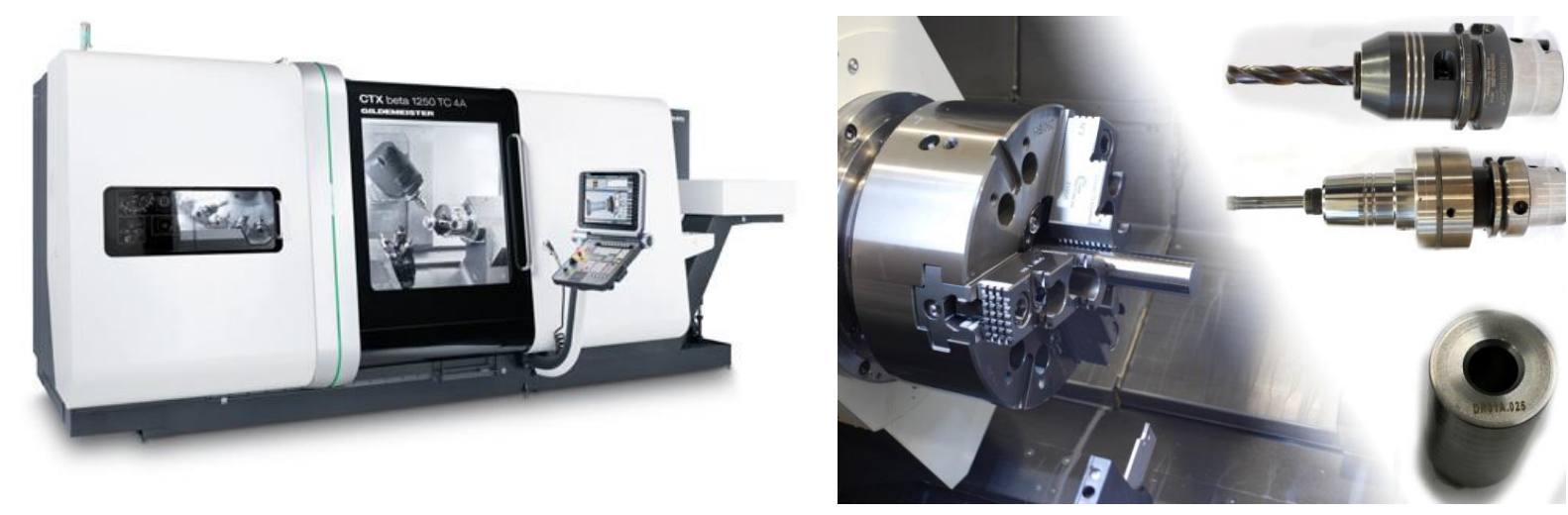

Fig. 1. Machining centre CTX beta 1250 TC 4A and workpiece with twist drill and reamer 


\begin{tabular}{|c|c|c|c|c|c|c|c|c|c|c|}
\hline \multirow{4}{*}{ 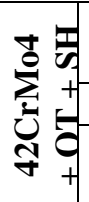 } & $\begin{array}{c}\text { Chemical } \\
\text { element }\end{array}$ & C & Mn & Si & $\mathbf{P}$ & $\mathbf{S}$ & $\mathrm{Cr}$ & Mo & $\mathbf{C u}$ & Al \\
\hline & $\%$ representation & 0.43 & 0.85 & 0.19 & 0.021 & 0.020 & 1.14 & 0.17 & 0.24 & 0.012 \\
\hline & Mechanical & \multicolumn{2}{|c|}{ Rm [MPa] } & \multicolumn{2}{|c|}{ Rp 0.2 [MPa] } & A [\%] & \multicolumn{2}{|c|}{$\mathbf{Z}[\%]$} & \multicolumn{2}{|c|}{$\mathrm{Kv}[\mathrm{J}] \mathbf{2 0}^{\circ} \mathrm{C}$} \\
\hline & properties & \multicolumn{2}{|c|}{1036} & \multicolumn{2}{|c|}{880} & 15.1 & \multicolumn{2}{|c|}{58} & \multicolumn{2}{|c|}{82} \\
\hline
\end{tabular}

Table 1. Chemical composition and mechanical properties of steel 42CrMo4

\subsection{Production process}

There was used 6 blade reamer with brazed cutting edges from cermet. The reamer was clamped into tool holder with possibility to change eccentricity of the tool tip. This system is called Compensation tool holder. Production process is in the Table 2.

\begin{tabular}{|c|c|c|c|c|}
\hline Nr. of operation & 1. & 2. & 3. & 4. \\
\hline $\begin{array}{l}\text { Technology } \\
\text { operation }\end{array}$ & Spot-drilling & Drilling & Chamfering & Reaming \\
\hline Dimension [mm] & $\varnothing 3 \times 1.5$ & $\varnothing 11.8 \times 60$ & $0.5 \times 45^{\circ}$ & $\varnothing 12 \mathrm{H} 7 \times 50$ \\
\hline $\begin{array}{l}\text { Material of the } \\
\text { cutting tool }\end{array}$ & $\begin{array}{c}\text { Sintered carbide } \\
\text { coated TiAlN }\end{array}$ & $\begin{array}{l}\text { Sintered carbide } \\
\text { coated TiAlN }\end{array}$ & $\begin{array}{c}\text { Sintered carbide } \\
\text { coated TiN }\end{array}$ & Cermet \\
\hline Number of blades & 2 & 2 & 1 & 6 \\
\hline $\mathbf{v}_{\mathrm{c}}[\mathrm{m} / \mathrm{min}]$ & 50 & 80 & 100 & \multirow{2}{*}{ Variables } \\
\hline f [mm/rev.] & 0.05 & 0.19 & 0.1 & \\
\hline
\end{tabular}

Table 2. Production process of the experiment

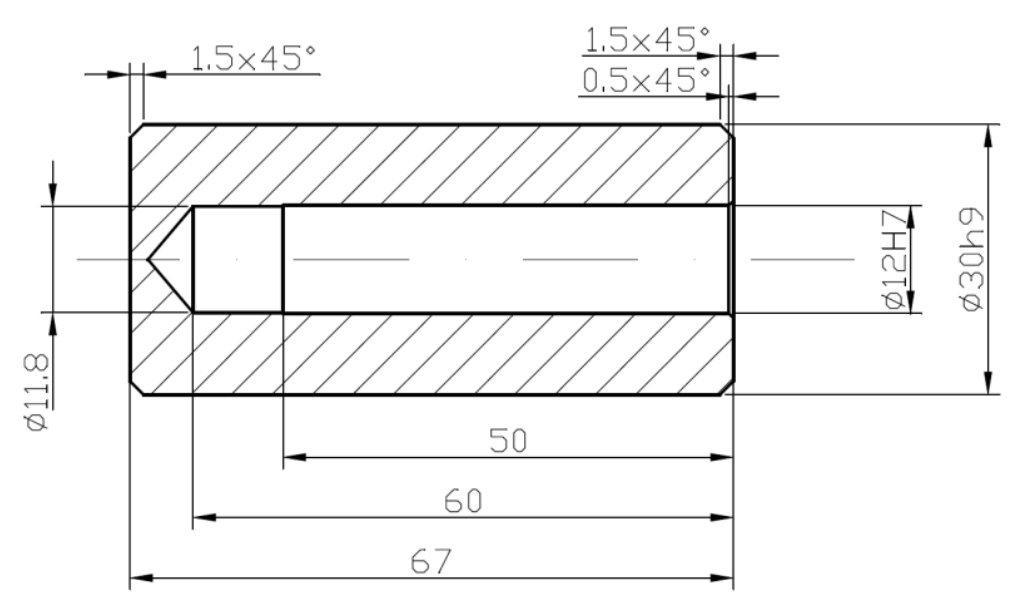

Fig. 2. Drawing of the sample

\subsection{Design of Experiment}

To evaluate the influence of single factors on quality of reamed hole there was chosen Central Composite Design with orthogonal blocking. This type of experimental plan is possible to detect nonlinear relation. The design of experiment takes into account 4 factors and every factor has 5 levels. The main advantage of CCD plan is small number of samples, to be specific 26 samples.

\begin{tabular}{|c|c|c|c|c|c|c|c|}
\hline \multirow{2}{*}{ Code } & Labelling & \multirow{2}{*}{ Unit } & \multicolumn{5}{|c|}{ Level of the factor } \\
\cline { 4 - 8 } & & $\mathbf{- \alpha}$ & $\mathbf{- 1}$ & $\mathbf{0}$ & $\mathbf{+ 1}$ & $+\boldsymbol{\alpha}$ \\
\hline $\mathrm{x}_{1}$ & $\begin{array}{c}\mathrm{v}_{\mathrm{c}} \\
\text { (cutting speed) }\end{array}$ & $\mathrm{m} / \mathrm{min}$ & 150 & 160 & 180 & 200 & 210 \\
\hline $\mathrm{x}_{2}$ & $\begin{array}{c}\mathrm{f} \\
\text { ffeed rate) }\end{array}$ & $\mathrm{mm} / \mathrm{rev}$ & 0.6 & 0.64 & 0.72 & 0.8 & 0.84 \\
\hline $\mathrm{x}_{3}$ & $\begin{array}{c}\mathrm{v}_{\mathrm{f}} \\
\text { (reverse feed) }\end{array}$ & $\mathrm{mm} / \mathrm{min}$ & 15 & 20 & 30 & 40 & 45 \\
\hline $\mathrm{x}_{4}$ & eccentricity & $\mu \mathrm{m}$ & 2 & 4 & 8 & 12 & 14 \\
\hline
\end{tabular}

Table 3. Experimental plan 


\section{Experimental results}

\subsection{Cylindricity}

Cylindricity of entire experiment were measured by Taylor Hobson TalyRond 585 roundness and form measurement instrument. The measured specimen was clamped in three-jaw chuck. Total measured height of the cylinder is a bit smaller than reamed hole height, because the measuring arm tip radius must be taken into calculation. Measuring arm with tip radius $2 \mathrm{~mm}$ was used for measurement. The measured height was divided into five levels and totally is the cylinder calculated from those five cross-sections using Least squares method.

Our goal was to approve the influence of selected parameters on the reamed hole cylindricity. We used a central composite design of the experiment that allows finding a mathematical model, which describes our response (cylindricity) in dependency on the process inputs, so called factors - cutting speed, tool tip eccentricity, feed. The first step in measured data evaluation, using mathematical model, is its creation by for example regression analysis and then its evaluation. Model suitability analysis is in Table 4.

\begin{tabular}{|c|c|}
\hline Parameter & Value \\
\hline RSquare & 0.644137 \\
\hline RSquare Adj & 0.555172 \\
\hline Root Mean Square Error & 1.579146 \\
\hline Mean of Response & 6.918407 \\
\hline Observations (or Sum Wgts) & 26 \\
\hline
\end{tabular}

Table 4. Regression model suitability analysis

We can see that the adjusted index of determination (Rsquare adj.) is only 0.55 that means that our mathematical model cannot explain approx. $44.5 \%$ of cylindricity variability. We can say that our selected reaming process inputs have only $55.5 \%$ influence on the cylindricity value. Let us have a look at model adequacy analysis, which was done by ANOVA. The results are in Table 5. The probability smaller than significance level (0.05) tells us that there is at least one mathematical model parameter that has an influence on investigated variable (in our case the cylindricity).

\begin{tabular}{|c|c|c|c|c|c|}
\hline Source & DF & Sum of Squares & Mean Square & F Ratio & Prob $>$ F \\
\hline Model & 5 & 90.27569 & 18.0551 & 7.2403 & 0.0005 \\
\hline Error & 20 & 49.87404 & 2.4937 & & \\
\hline C. Total & 25 & 140.14974 & & & \\
\hline
\end{tabular}

Table 5. Regression model ANOVA

The next step in the model analysis is the Lack of fit test. (See Table 6) This test proves us that the regression model perceives enough the observed dependency. It tests that the variability of residuals in comparison to variability of the values inside of groups. A null hypothesis tells that the residuals variability is smaller or equal to the variability of values inside of groups. The alternate hypothesis tells us that the variability of residuals is greater than inside of groups. The value of Fisher's test criterion is greater than significance level (0.05) we can assume that we do not have enough of evidence to reject null hypothesis. For us it means that our regression model is sufficient.

\begin{tabular}{|c|c|c|c|c|c|c|}
\hline Source & DF & Sum of Squares & Mean Square & F Ratio & Prob > F & Max RSq \\
\hline Lack of Fit & 9 & 20.649730 & 2.29441 & 0.8636 & 0.5840 & 0.7915 \\
\hline Pure Error & 11 & 29.224315 & 2.65676 & & & \\
\hline Total Error & 20 & 49.874045 & & & & \\
\hline
\end{tabular}

Table 6. Lack of Fit test

We have sufficient and adequate regression model and now we can calculate model parameters estimation (Table 7).

\begin{tabular}{|c|c|c|c|c|c|c|c|}
\hline Term & Estimate & Std Error & t Ratio & Prob $>|\mathbf{t}|$ & Lower 95 \% & Upper 95 \% & VIF \\
\hline Intercept & 6.9184069 & 0.309696 & 22.34 & $<0.0001$ & 6.2723923 & 7.5644215 &. \\
\hline $\mathrm{x}_{1}$ & 0.3032367 & 0.349641 & 0.87 & 0.3961 & -0.426102 & 1.0325751 & 1 \\
\hline $\mathrm{x}_{2}$ & -0.731483 & 0.349641 & -2.09 & 0.0494 & -1.460821 & -0.002144 & 1 \\
\hline $\mathrm{x}_{3}$ & -0.343103 & 0.349641 & -0.98 & 0.3382 & -1.072441 & 0.3862352 & 1 \\
\hline $\mathrm{x}_{2} \cdot \mathrm{x}_{1}$ & -1.767653 & 0.394787 & -4.48 & 0.0002 & -2.591163 & -0.944143 & 1 \\
\hline $\mathrm{X}_{2} \cdot \mathrm{x}_{1} \cdot \mathrm{x}_{3}$ & 1.2522606 & 0.394787 & 3.17 & 0.0048 & 0.4287504 & 2.0757709 & 1 \\
\hline
\end{tabular}

Table 7. Regression model parameters estimation 
From Table 7 we can see several facts. Firstly, at 5\% significant level, the intercept has influence on the cylindricity value. This represents all other factors that were considered as fixed or neglected, or used factors intervals, other uncalculated errors etc. Next, other factors that have statistical influence on the cylindricity value are terms $\mathrm{x}_{1}$ (cutting speed), $x_{2}$ (feed), $x_{3}$ (reverse feed), combination of cutting speed and feed and at the end is the combination of cutting speed, feed and reverse feed. What is interesting, the eccentricity of the reamer does not have influence on the cylindricity as independent factor neither as in combination with other factor. When we have a closer look at percentage influence of factors on the hole cylindricity, we can see that the intercept has $66 \%$. The interaction of cutting speed and feed $13 \%$, interaction of cutting speed, feed and reverse feed $9 \%$, cutting speed has $3 \%$ of influence, feed influences the cylindricity from $6 \%$ and the reverse feed has $3 \%$ influence on the cylindricity.

At the end we have the prediction model of reamed hole cylindricity converted to the real factors value:

$$
\begin{array}{r}
C y l=207.519 \times f+0.865 \times v_{c}+2.983 \times v_{f}-1.187 \times f \times v_{c}-4.174 \times f \times v_{f} \\
-1.667 \times 10^{-2} \times v_{c} \times v_{f}+2.322 \times 10^{-2} \times f \times v_{c} \times v_{f}-143.628
\end{array}
$$

For maximal complexity of regression analysis and selected regression model validation, it is necessary to evaluate residuals between measured and predicted values for their distribution and autocorrelation. The autocorrelation of residuals was tested using Durbin-Watson test and it showed us that there is no autocorrelation of residuals. The normal distribution of residuals we tested by Shapiro-Wilk test and it showed positive result for us, too. The model residuals have normal distribution. By those two tests, we approve that the model is statistically and numerically correct.

From analysis of regression model we can say that cutting speed as independent factor does not have significant influence (at statistical significance level 5\%) on the reamed hole cylindricity. But, it is significantly involved in several combinations with other factors, see Fig. 3.
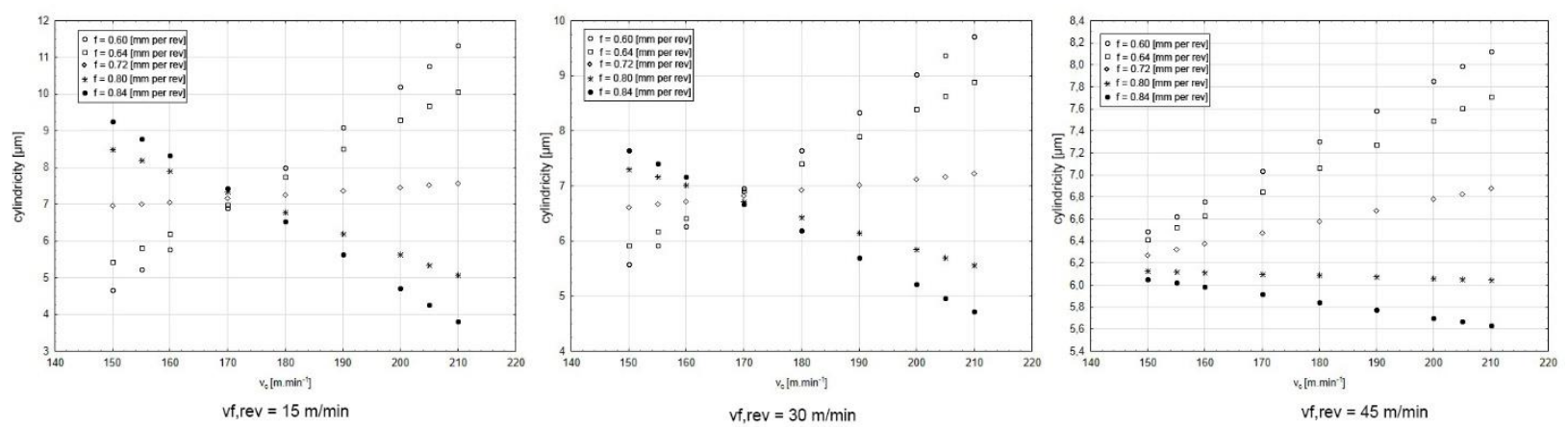

Fig. 3. Influence of cutting speed on cylindricity

The feed rate has its own influence as an independent factor with portion of $6 \%$. It is also involved in interactions with cutting speed and reverse feed rate. Graphical representation of this influence is in Fig. 4.
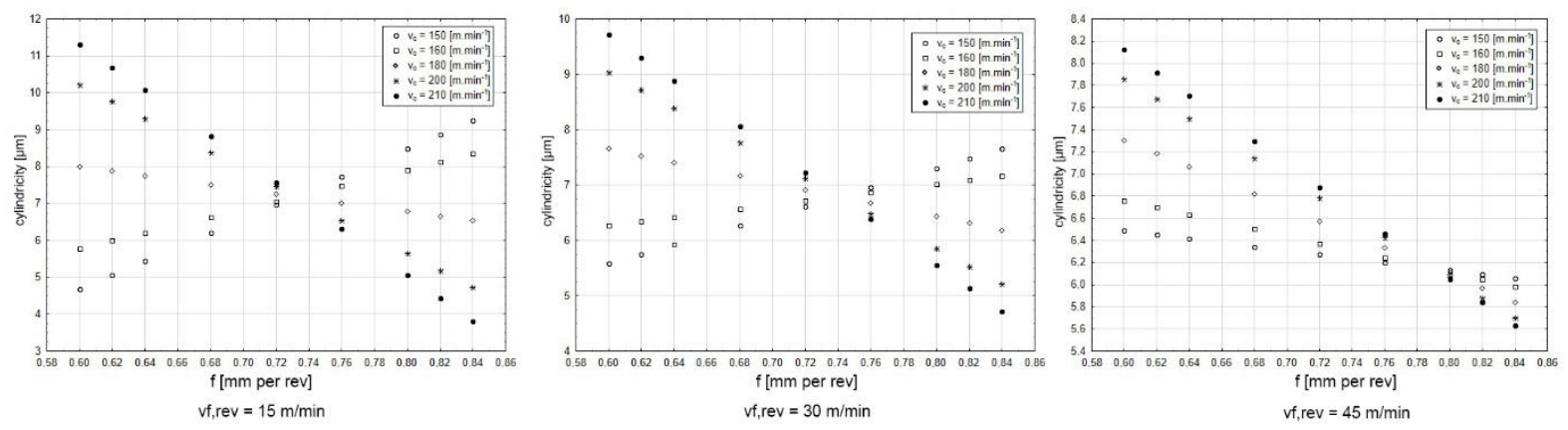

Fig. 4. Influence of feed rate on cylidricity

\subsection{Surface roughness $R a$}

Measured values of surface roughness reached very low deviation for all 26 samples. Machined surface of reamed hole is possible to consider as homogeneous. Surface roughness $\mathrm{Ra}$ was from 0.2 to $0.6 \mu \mathrm{m}$. These phenomena can be explained by material of cutting tool. High cutting speeds, high feed rates and internal cooling are suitable for cermet reamer. Under these conditions the reamer works more reliably. 


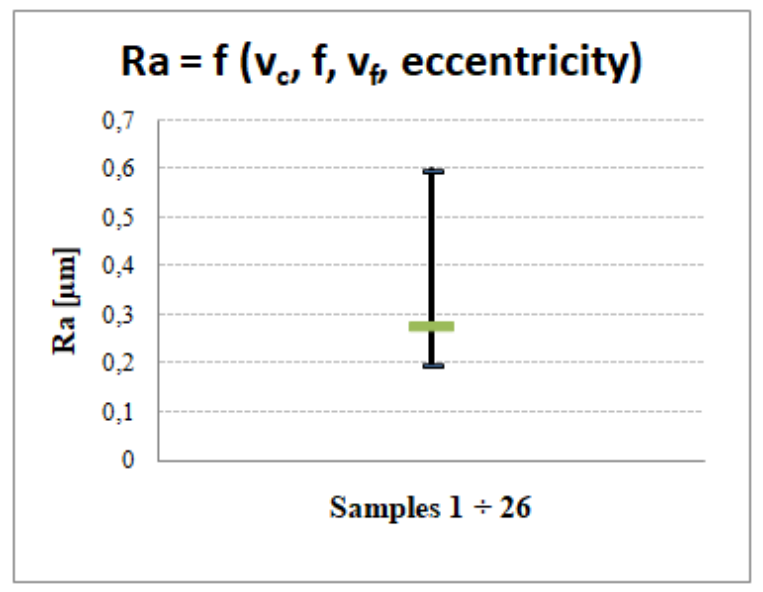

Fig. 5. Influence of tested factors on surface roughness Ra

\subsection{Real diameter of reamed hole}

Previous experiment did not prove the influence of eccentricity on cylindricity and surface roughness of reamed hole. So the new set of experiments was done and its conditions are in the Table 8 . There are also values of real diameter which was measured at the top (D_up) and at the bottom (D_down) of the reamed hole. These values brightly show, that eccentricity of the tool tip does not influence quality of reamed hole. Eccentricity has influence mainly on tool wear and on position error. Clamping system is not perfectly stiff and overhanging of reamer is too big. If the tool was shorter (lower overhanging), eccentricity would influence measured parameters.

\begin{tabular}{|c|c|c|c|c|}
\hline \multirow{2}{*}{ O.Nr. } & \multirow{2}{*}{ Clamping system } & \multirow{2}{*}{ Eccentricity [ $\mathbf{\mu m}]$} & \multicolumn{2}{|c|}{ Measured diameter [mm] } \\
\cline { 4 - 5 } & & 4 & D_up & D_down \\
\hline 1. & Compensation tool holder & 12,0168 & 12,0179 \\
\hline 2. & Compensation tool holder & 12 & 12,0166 & 12,0178 \\
\hline 3. & Compensation tool holder & 26 & 12,0169 & 12,0177 \\
\hline 4. & Hydraulic tool holder & 26 & 12,0168 & 12,0179 \\
\hline
\end{tabular}

Table 8. Influence of tool tip eccentricity on real diameter of reamed hole

\section{Conclusion}

This article dealt with influence of four factors (cutting speed, feed rate, reverse feed and eccentricity) on cylindricty, surface roughness and real diameter of reamed hole. The reamed hole was blind and was made by six blade reamer with brazed cermet cutting edges. The tool wear was controlled and was not take into account. The experiment proved that:

- the most significant component is constant. This constant includes everything what was not take into account. It means, for example, wrong range of cutting parameters; something what was changing during the experiment and we did not know about it; something what we could not influence, etc.

- main influence on cylindricity has feed, interaction of feed rate and cutting speed and interaction between cutting speed, feed rate and reverse feed. The higher feed rate and cutting speed the lower cylindricity.

- experimental factors had not any influence on surface roughness Ra. Cermet reamer proved produce homogeneous surface. It is because of cutting material. Cermet is called "queen" of finished surfaces.

- eccentricity did not influence the real diameter of reamed hole. The main reason is stiffness of clamping system and overhanging of the tool. At the first contact of the tool with the hole (chamfered part), the reamer was led by drilled hole. If the reamer was shorter (lower overhanging), we would suppose the bigger influence of eccentricity on real diameter. Eccentricity has influence mainly on tool wear. The higher eccentricity the lower tool life.

This experiment brightly proved that many factors has to be controlled before experiment. Statistical methods design of experiments can help us to find parameters which can influence the response and also save out time and money. On the other hand we have to know very well basic data, to understand the way of DoE, to know as much as possible about relations between dependent and independent variable, to set up right range of factors, etc. If we neglect something we will know it at value of constant. If the constant is significant we can start again. However, every mistake which we will do it, probably we will never repeat it and this mistake will move us forward.

Future plans are based on results presented in this paper. So it is necessary to choose right factors and their range. After that, we will repeat the experiment and evaluate the data. Hopefully, we will be able to express the influence of input parameters on the response. 


\section{Acknowledgement}

The present contribution has been prepared under project LO1502 'Development of the Regional Technological Institute "under the auspices of the National Sustainability Programme I of the Ministry of Education of the Czech Republic aimed to support research, experimental development and innovation.

\section{References}

[1] Fulemova, J. \& Rehor, J. (2016). Reaming of very precise and deep holes with cermet reamer. 27th DAAAM International Symposium on Intelligent Manufacturing and Automation 2016, Volume 27, Issue 1, 2016, Pages 275282

[2] Klaic, M.; Staroveski, T. \& Udiljak, T. (2014). Tool Wear Classification Using Decision Treesin Stone Drilling Applications: A Preliminary Study. 24th DAAAM International Symposium on Intelligent Manufacturing and Automation 2014. Volume 69, Pages 1326 - 1335. DOI: 10.1016/j.proeng.2014.03.125.

[3] Roub, J. (2017). Influence of selected technological factors of machining to surface integrity of precise holes cutting conditions during reaming. Plzen. Diploma thesis. ZCU v Plzni.

[4] Bhattacharyya, O.; Kapoor, S.G. \& Devor, R. E. (2006). Mechanistic model for the reaming process with emphasis on process faults. International Journal of Machine Tools and Manufacture. 2006, 46(7-8), 836-846. DOI: 10.1016/j.ijmachtools.2005.07.022

[5] Hauer, T.; Haydn, M. \& Abele, M. (2012). Influence of a diagonal pre-drilled hole on hole quality during the reaming process using multiblade tools. Journal of the Brazilian Society of Mechanical Sciences and Engineering. Special issue 2, 2012, Vol. XXXIV, pp. 569 - 573

[6] Towfighian, S.; Behdian, K.; Papini, M.; Saghir, Z.; Zalzal, P. \& Beer, J. (2006). Finite element modeling of low speed reaming vibrations with reamer geometry modifications. DOI: 10.1007/s10845-007-0038-4.

[7] Bezerra, A. A.; Machado, A. R.; Souza, A. M. Jr. \& Ezugwu, E. O. (2000). Effects of machining parameters when reaming aluminium-silicon (SAE 322) alloy . DOI: 10.1016/S0924-0136(01)00561-1.

[8] Müller, P.; Genta, G.; Barbato, G.; Chiffre, L. \& Levi, R. (2012) . Reaming process improvement and control: An application of statistical engineering. DOI: 10.1016/j.cirpj.2012.07.005. 